\title{
Solar Dish/Engine Systems
}

These systems, with net solar-to-electric conversion efficiencies reaching $30 \%$, can operate as stand-alone units in remote locations or can be linked together in groups to provide utility-scale power.

Solar dish/ engine systems convert the energy from the sun into electricity at a very high efficiency. Using a mirror array formed into the shape of a dish, the solar dish focuses the sun's rays onto a receiver. The receiver transmits the energy to an engine that generates electric power.

Because of the high concentration ratios achievable with parabolic dishes and the small size of the receiver, solar dishes are efficient at collecting solar energy at very high temperatures. Tests of prototype systems and components at locations throughout the United States have demonstrated net solar-to-electric conversion efficiencies as high as $30 \%$. This is significantly higher than any other solar technology.

\section{Benefits}

Solar dish/engine systems have environmental, operational, and potential economic advantages over more conventional power generation options because they:

- produce zero emissions when operating on solar energy;

- operate more quietly than diesel or gasoline engines;

- are easier to operate and maintain than conventional engines;

- start up and shut down automatically; and

- operate for long periods with minimal maintenance.

Because of their size and durability, solar dish/engine systems are well-suited for nontraditional power generation. Individual units range in size from 10 kilowatts to 25 kilowatts. They can operate independently of power grids in remote sunny locations for uses such as pumping water and providing power to people living in isolated villages.

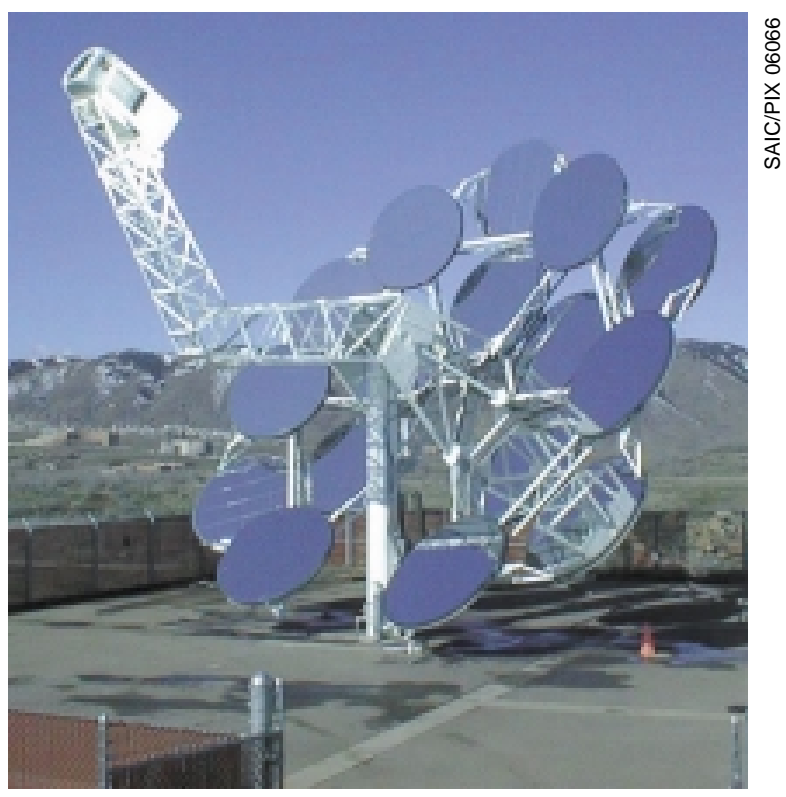

SAIC installed this second-generation prototype dish/engine system, rated at 25 kilowatts $(\mathrm{kW})$, at a Sun`Lab test site in 1998.

Dish/engine systems also can be linked together to provide utility-scale power to a transmission grid. Such systems could be located near consumers, substantially reducing the need for building or upgrading transmission capacity. Largely because of their high efficiency, the cost of these systems is expected to be lower than that of other solar systems for these applications.

\section{The Opportunity}

The market timing for solar dish/engine technology is promising, both at home and abroad. In the U. S. Southwest, it is a leading candidate for the renewable energy "portfolio standards" recently adopted in Arizona and Nevada.

At the same time, worldwide demand for electric power is growing rapidly as many 


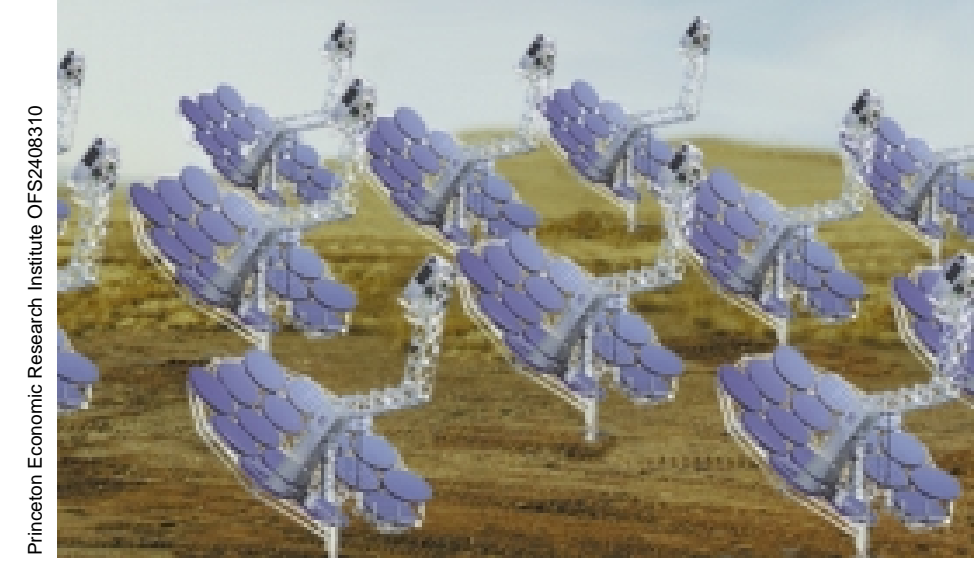

Artist's rendering of a field of dish/engine systems. Such configurations can provide megawatts of power.

countries are extending their electric power systems, reaching more and more of their citizens. Still, one-third of the world's inhabitants, many in sunny semi-arid regions, live in homes without electricity. Cleaner, simpler, and more versatile than conventional diesel or gasoline engines, solar dish/engine systems will help open up nontraditional markets for electricity to serve these people.

\section{Development at the Laboratories}

To help U.S. industry take advantage of these opportunities, Sun Lab provides the technical support and solar expertise necessary to help industry achieve commercialization. Sun Lab carries out research and development of advanced technology required to make future systems more efficient, long-lived, and cost-effective by:

- developing advanced solar concentrators and solar receivers;

- performance testing of components and elements of emerging and advanced systems; and

- evaluating system design and performance tradeoffs.

\section{Industry Partners}

Public investment in development of dish/engines is highly leveraged with that of private industry. For example, Science Applications International Corp. (SAIC) of Golden, Colorado, and Stirling Thermal Motors, Inc. (STM) of Ann Arbor, Michigan, have invested \$8 million through a joint venture with the U.S. Department of Energy (DOE) to develop a 25-kW system for utility applications. By the end of 1998, SAIC will install the first of five second-generation prototypes to demonstrate performance and lifetime in a utility-operating environment. In 1999, SAIC will deploy additional dish/engines with a combined capacity of one megawatt to establish the readiness of the technology for commercial markets. Such installations will also allow for development of the initial manufacturing capability for the first commercial sales.

Based on the recognition of the potential of dish/engine technology by other U.S. industry, DOE is currently expanding new cost-shared activities that involve major industry players such as Boeing Corporation of Huntsville, Alabama, and Allied Signal Corporation of Tempe, Arizona. These new joint ventures will expand the base of U.S. industry participating in dish/engine technology, accelerate the pace of technology development, and ensure a stronger U.S. share in developing world markets.
For on-line information about the U.S. Department of Energy's Concentrating Solar Power Program, please visit its web site: http://www.eren.doe.gov/sunlab

For more information on renewable energy or for additional copies of this brochure, contact the Energy Efficiency and Renewable Energy Clearinghouse (EREC): 1-800-DOE-EREC (363-3732)

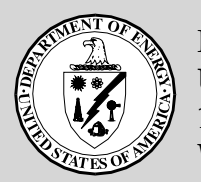

Produced for the

U.S. Department of Energy (DOE) 1000 Independence Avenue, S.W. Washington, DC 20585-0121

Produced by Sun`Lab:

Bringing together solar energy expertise from Sandia National Laboratories and the National Renewable Energy Laboratory, DOE national laboratories.

DOE/GO-10097-407 April 1998

Printed on recycled paper 